\title{
Practical application of the RUTA safe pool-type nuclear reactor to demonstrate the advantages of atomic energy use
}

\author{
A. Romenkov \\ N.A. Dollezhal Research and Development Institute of Power \\ Engineering (NIKIET) \\ Moscow, Russian Federation \\ E-mail: nikiet@nikiet.ru
}

\begin{abstract}
The concept of the RUTA water-cooled, water-moderated pool-type nuclear reactor is presented. The basic findings of the RUTA-70 pilot district-heating plant in the science town of Obninsk, Kaluga Region, Russia, and its capabilities for nuclear technology research purposes, are shown. The basic technical data of the reactor facility are presented and its design is described in brief. The potential of using low-grade heat in the town's heating networks is shown. The technical aspects of using the reactor's thermal power in a thermal seawater desalination facility are considered. Issues related to the application of the nuclear reactor as a neutron source for implementing modern nuclear technologies are discussed.
\end{abstract}

Keywords: nuclear reactor; district heating; seawater desalination; nuclear technologies.

Reference to this paper should be made as follows: Romenkov, A. (2009) 'Practical application of the RUTA safe pool-type nuclear reactor to demonstrate the advantages of atomic energy use', Int. J. Nuclear Desalination, Vol. 3, No. 4, pp.390-400.

Biographical notes: A. Romenkov graduated from the Moscow Power Engineering Institute in Russia in 1980. He joined N.A. Dollezhal Research and Development Institute of Power Engineering (NIKIET) in the same year as a Nuclear Engineer. He passed the stairs of service hierarchy in the institute - Engineer, Researcher, Senior Researcher, Head of the laboratory. He participated in the designs of nuclear installations such as the Russian channel and vessel type nuclear reactors. He has been serving the institute as a Director of Nuclear Power Reactors Department since 1998. His duties include research and development of nuclear reactor plants, development of safety analysis reports for nuclear facility, commissioning and decommissioning of nuclear objects, development of nuclear waste encapsulation methods, methods for spent fuel handling, field supervision of nuclear facility, development and fulfilling of quality assurance programme and communications with nuclear regulatory body of the Russian Federation.

The aim of activity is to provide Russian NPP operators with proper designs to support NPP site in a safe condition and enhancing the economic indices. 


\section{Introduction}

The efforts to develop the RUTA pool reactor, launched in the late 1980s, met the challenge of building an ultimately safe, structurally simple, cheap and easy-to-operate utility reactor to provide Russian cities with heating and hot water supply services. The concept of using a pool reactor as part of a Nuclear District-Heating Plant (NDHP) is based on a long-term positive experience in designing and operating pool research reactors: there are 225 research reactors in the power range from several kilowatts to 70 MW operated worldwide, including 23 reactors designed by the N.A. Dollezhal Research and Development Institute of Power Engineering (NIKIET), of which 7 are located in Russia. The simple design and low coolant parameters inherent to a pool reactor make it highly reliable, with the absence of the potential for severe accidents being the assurance of radiation safety, which makes it possible to deploy facilities in the immediate proximity of consumers.

The conceptual design of the RUTA-20 (a reactor facility for heat supply with atmospheric pressure in the reactor), with a thermal power of $20 \mathrm{MW}$, was issued in 1990. This development was given prominence at the competition among the designs of small nuclear plants held in 1991-1992 under the auspices of the Russian Nuclear Society.

Later on, the RUTA design options with a thermal power from 10 to $55 \mathrm{MW}$ were developed at a conceptual level.

The concept of using the RUTA pool reactor to desalinate seawater was developed in 1997. This included a reactor core consisting of two portions: the central part, similar to that of conventional research reactors, and the lateral part, formed by an assembly of modular channels capable of generating high-pressure steam to drive a small turbo-generator set. This facility produced up to $65 \mathrm{MW}$ of thermal power and over $3 \mathrm{MW}$ of electric power to operate the desalination plant pumps. When multistage distillation facilities were used, the fresh water output reached $35000 \mathrm{~m}^{3} /$ day (Romenkov et al., 1997).

The results of using the RUTA pool reactor's thermal power to produce cold water for air-conditioning purposes in hot-climate countries were published the same year (Adamov et al., 1997).

To upgrade the research equipment of Russia's Federal Nuclear Center in Obninsk, Kaluga Region, proposals were developed in 2001-2004 for the 70 MWt RUTA multipurpose reactor facility. This project combines the functions of an NDHP and a research reactor, including potential use of the reactor as a neutron source for medical and technological applications.

The concept of a multipurpose complex based on the RUTA-IT reactor facility of $35 \mathrm{MWt}$ was developed for the Nuclear Technologies Park in the Republic of Kazakhstan.

Thus there has been a sustained public interest in the RUTA project since 1980, around three decades. This can be attributed to the high safety features of the reactor and its ability to perform a great deal of research and economic functions. So why has it not been built in Russia to date? The major reason is certainly the Chernobyl disaster, which virtually led to the suspension of the development of nuclear power worldwide. The second reason is that gas used for heating in Russia is relatively cheap. At present, as domestic gas prices are nearing international market prices, the project has been facing 
renewed interest. The third reason is that nuclear installations cannot be legally privatised in Russia. The latter is important because the RUTA reactor produces municipal-scale heat and is scarcely attractive to the key private players in large regional power markets.

\section{Design of the RUTA-70 reactor}

The RUTA is a pool reactor facility with a water-cooled, water-moderated reactor with a thermal power of $70 \mathrm{MWt}$ (Figure 1).

Figure 1 Sectional view of the reactor department

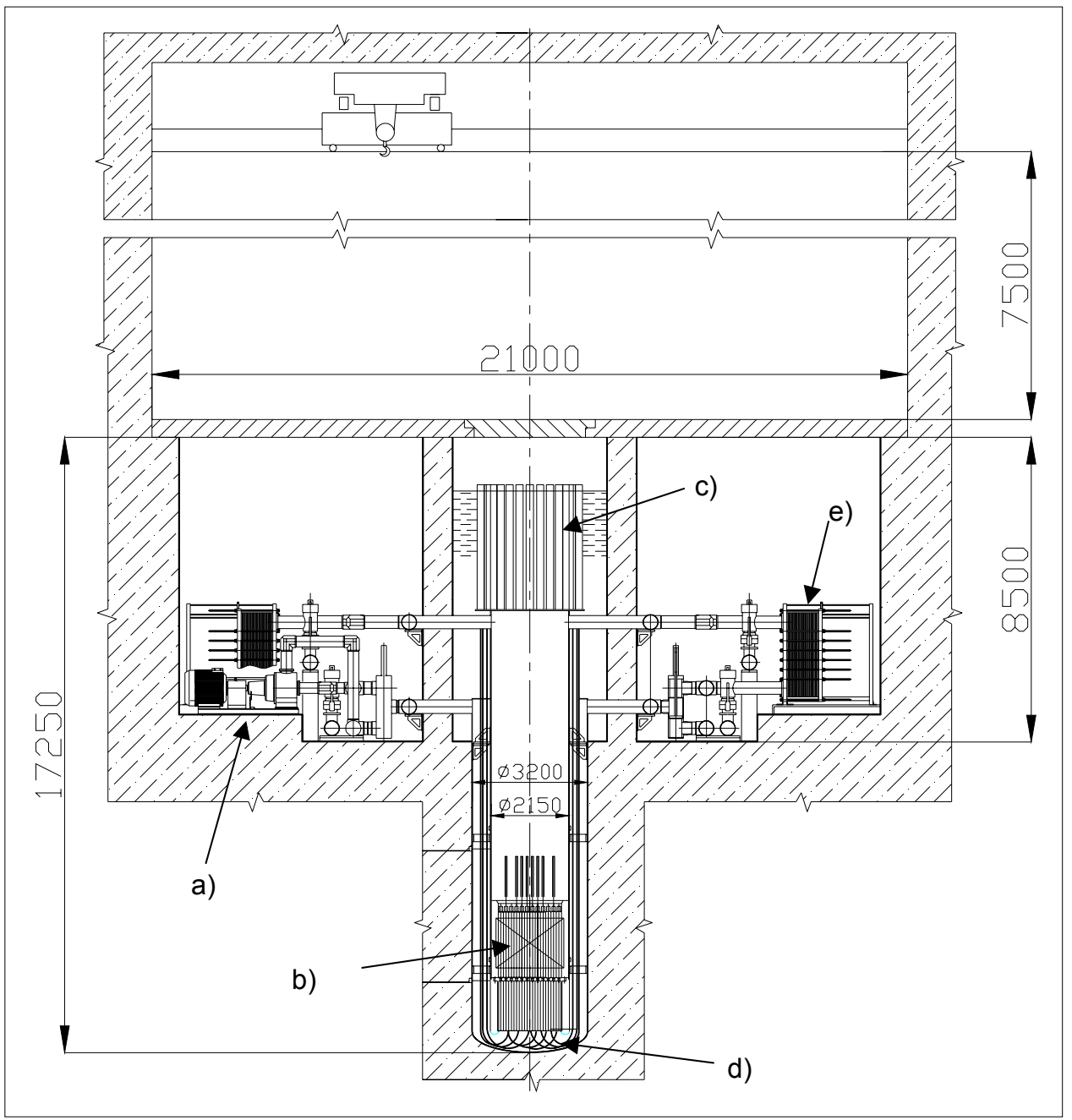


The following design approach has been taken with respect to the reactor's major components and the selection of the primary circuit flow area geometry:

- In the power range from the lowest level to $\approx 30 \% \mathrm{~N}_{\text {nom }}$ and in the cooldown mode (both regular and emergency), the core is cooled and heat is transferred in the primary heat exchangers to the secondary coolant with a natural coolant circulation in the reactor.

- For the heat loads from $\approx 30 \% \mathrm{~N}_{\text {nom }}$ to $100 \% \mathrm{~N}_{\text {nom }}$, the connection of the reactor pumps is provided and the flow rate is increased in the in-pile circulation circuit.

The forced circulation mode is enabled by axial pumps installed in the natural circulation circuit as a bypass (Figure 1a). Then the coolant goes to the reactor core (Figure 1b), where water is heated. The reactor power is regulated using the Control and Protection System (CPS) drives (Figure 1c), which are in the reactor pool water. It should be noted that the CPS absorber cluster rods are flexible and the clusters as such are controlled from the core bottom (Figure 1d). The scram rods have an individual two-position hydraulic drive enabling full withdrawal or full insertion of the rods. Heat is removed from the core in plate-type heat exchangers from the company A-Laval (Figure 1e).

Natural circulation is capable of ensuring core cooling at power levels up to $50 \% \mathrm{~N}_{\text {nom. }}$. At the same time, use of the pumps installed in the reactor circuit and the application of forced coolant circulation for operations at power levels of $30 \%$ to $100 \%$ $\mathrm{N}_{\text {nom }}$ make it possible to increase the coolant flow rate in the primary circuit and raise the downcomer temperature by reducing the water thermal gradient in the reactor core.

Table 1 Basic technical data of the RUTA-70 reactor

\begin{tabular}{ll}
\hline Maximum thermal power of the reactor $\left(\mathrm{N}_{\text {nom }}\right), \mathrm{MW}$ & 70 \\
Coolant circulation in the primary circuit & \\
- up to $30 \% \mathrm{~N}_{\text {nom }}$ & Natural \\
- from $30 \%$ to $100 \% \mathrm{~N}_{\text {nom }}$ & Forced \\
Core heat-removal mode & Two-circuit \\
Pressure in the air space over the reactor & Atmospheric \\
Core dimensions (equivalent diameter/height), $\mathrm{m}$ & $1.42 / 1.4(1.53)$ \\
Fuel & $\mathrm{UO}_{2} ;$ cermet $\left(0.6 \mathrm{UO}_{2}+0.4 \mathrm{Al}\right.$ alloy) \\
Uranium-235 enrichment of fuel, $\%$ & 4.2 \\
Uranium load in the reactor core, $\mathrm{kg}$ & 4165 \\
Number of Fas & 91 \\
Fuel life, eff. days & 2332 \\
Cycle length at a capacity factor of 0.7, years & 3 \\
Fraction of core reloaded each cycle & $1 / 3$ \\
Water amount in the reactor tank, $\mathrm{m}^{3}$ & 250 \\
Core temperature at natural circulation mode (inlet/outlet), ${ }^{\circ} \mathrm{C}$ & $75 / 101$ \\
\hline
\end{tabular}

The reactor core is located at the bottom of the vessel cavity and consists of 91 hexagonal Fuel Assemblies (FAs) with fuel rods. Under consideration are two fuel element versions, one of the VVER-440 type and containing uranium dioxide fuel in a 
zirconium cladding, and the other being cermet-based $\left(\mathrm{UO}_{2}\right.$ granules in a silumin matrix with a $\mathrm{UO}_{2}$ volume fraction of 0.6 ) in a zirconium cladding. The FA structural material is a zirconium alloy. The FAs are arranged in a triangular lattice with a pitch of $147 \mathrm{~mm}$ and form a regular and symmetric system. The reactor core height for the first and the second fuel versions is $1400 \mathrm{~mm}$ and $1530 \mathrm{~mm}$ respectively. The equivalent diameter of the reactor core for both versions is $1420 \mathrm{~mm}$.

The basic technical data of the RUTA-70 reactor facility are presented in Table 1.

The spent fuel pool is situated next to the reactor and is connected with the reactor pool via the refuelling channel. Assemblies are reloaded manually beneath the water layer as in most research reactors.

\subsection{Application of the RUTA reactor for district heating}

A general solution to district-heating technology is the combined application of nuclear power sources (base-load generation) and conventional fossil fuel power sources (peak-load and intermediate-load generation).

This combined technology of operation of a nuclear reactor and standby-peaking boiler is suitable in districts which have sufficient outside electric power supply but lack fuel for heating plants (Figure 2).

Figure 2 Schematic of the nuclear heat source connection to the district-heating network



Studies to optimise the components of water-heating plants in heat supply systems prove the expediency of ensuring redundancy and thus attaining the required reliability through the use of fire-powered or electric water heaters (Figure 2d).

The RUTA reactor facility has a two-circuit layout. The primary circuit (Figure 2a) is an in-pile reactor core cooling circuit and the secondary circuit (Figure 2b) is an intermediate one that removes heat from the reactor and transfers it to the third circuit (Figure 2c), which is the consumer circuit, i.e., to the heating network. Heat is transferred 
from the primary circuit to the secondary circuit and from the secondary circuit to the third circuit through the leak-tight heat-exchange surfaces, which are used to avoid the spread of radioactive products from the reactor circuit to the consumer.

The smallest staffing of the operating shift is four persons. These are the NDHP shift supervisor, the chief reactor control engineer, a fitter-walker for normal operation systems and a duty electrician to attend to electrical devices and systems, instrumentation and control. The respective services are responsible for radiation monitoring during operation and repair. A supervising physician and a refuelling operator from a specialised organisation are added to the regular shift staff for the core fuelling, first core critical mass attaining, power startup and refuelling periods. Inspection and repair of the NDHP systems and components are done by hired personnel.

With managers, engineers and technicians working in one shift (a chemical engineer, an engineer for electrical devices and systems, an engineer for instrumentation and the industrial control) and the administrative staff taken into account, the total personnel number is about 40 persons.

\subsection{Application of the RUTA reactor as a neutron source}

Given the diversity of tasks and concerns faced by the research and production organisations of Obninsk, an important consideration that favours the construction of the RUTA facility in this city is that it can be used in multipurpose applications:

- $\quad$ in the production of a broad range of medical and commercial radionuclides

- in the neutron-transmutation doping of silicon monocrystals for modern microelectronics

- in the generation of neutron beams for ray therapy and Neutron-Capture Therapy (NCT)

- $\quad$ in the irradiation of thin polymer films for subsequent production of track membranes

- in the neutron-activation analysis of ores, minerals, etc.

For these applications, it is possible to fit the reactor with the following irradiation devices:

- $\quad$ irradiation channels in the reflector blocks

- not less than eight radioisotope production channels

- a channel for neutron-transmutation doping of silicon ingots

- two rabbit channels (pneumatic post) for neutron-activation analysis

- external irradiation devices with neutron beams

- $\quad$ one Fast-Neutron Therapy (FNT) channel

- $\quad$ one NCT channel

- one channel for the irradiation of polymer film used to produce track membranes. 
The channels of irradiation devices are situated above the reactor core in special tube structures which are lowered into the core. The horizontal neutron beam channels are used to produce track membranes and for medical purposes.

Table 2 presents the characteristics of fluxes for neutron groups, which are conditionally designated as fast (f), epithermal (et) and thermal (t), in the core centre and at the locations of special channels and devices at the beginning (b) and the end (e) of the operating cycle. The cells of reflector row 1 show the spread of the neutron flux values depending on the location of the cells and fuel burnup.

The adopted design approaches provide an in-pile arrangement of special-purpose channels and devices that ensures that the effects on the neutronic and fuel characteristics of the core are as small as possible while meeting the specific requirements of the parameters of the neutron fluxes in the irradiation channels and devices.

Table 2 Neutron fluxes in the reactor core centre and at the locations of irradiation channels and devices as of the beginning and the end of the core life-time, $10^{13} /\left(\mathrm{cm}^{2} \cdot \mathrm{s}\right)$

\begin{tabular}{|c|c|c|c|c|c|c|c|c|c|c|c|c|}
\hline \multirow{2}{*}{$\begin{array}{l}\text { Neutron energy } \\
\text { in the group }\end{array}$} & \multicolumn{2}{|c|}{ Central FA } & \multicolumn{2}{|c|}{$\begin{array}{c}\text { Reflector row } 1 \\
\text { (radioisotope } \\
\text { production } \\
\text { channels) }\end{array}$} & \multicolumn{2}{|c|}{$\begin{array}{c}\text { Silicon-doping } \\
\text { channel }\end{array}$} & \multicolumn{2}{|c|}{$\begin{array}{c}\text { FNT } \\
\text { channel, } \\
\text { bottom }(A l)\end{array}$} & \multicolumn{2}{|c|}{$\begin{array}{c}\text { NCT channel, } \\
\text { bottom (Al) }\end{array}$} & \multicolumn{2}{|c|}{$\begin{array}{l}\text { Graphite TM column } \\
\text { (layer in the } \\
\text { region of the water } \\
\text { downcomer) }\end{array}$} \\
\hline & $b$ & $e$ & $B$ & $e$ & $b$ & $e$ & $b$ & $e$ & $b$ & $e$ & $b$ & $e$ \\
\hline$\varphi_{\mathrm{f}}(0.1-10 \mathrm{MeV})$ & 12.1 & 7.6 & $1.0 \div 2.6$ & $1.4 \div 2.1$ & 0.13 & 0.16 & 1.3 & 1.5 & 0.83 & 1.0 & $7.71 \cdot 10^{11}$ & $7.86 \cdot 10^{11}$ \\
\hline$\varphi_{\mathrm{et}}(1 \mathrm{eV}-100 \mathrm{keV})$ & 5.8 & 3.7 & $1.1 \div 2.4$ & $1.3 \div 1.9$ & 0.11 & 0.13 & 1.2 & 1.4 & 0.76 & 0.89 & - & - \\
\hline$\varphi_{\mathrm{t}}(<1 \mathrm{eV})$ & 3.8 & 2.6 & $7.0 \div 9.6$ & $6.0 \div 6.5$ & 1.8 & 2.3 & 4.6 & 5.4 & 2.8 & 2.9 & $1.28 \cdot 10^{13}$ & $1.36 \cdot 10^{13}$ \\
\hline
\end{tabular}

\subsection{Nuclear desalination of seawater using the RUTA reactor}

The application of the RUTA reactor as a heat source for distillation plants is considered (Figure 3). Seawater is desalinated in Distillation Desalination Plants (DDP) with horizontal-tube film units. The relatively low temperature of the heat generated by the reactor has required special designs to provide for a distillate output of the Nuclear Desalination Complex (NDC) that is as high as possible. The layout, combining a reactor facility and a desalination plant, includes steam-generating equipment. The steam generation circuit is designed as the theard circuit loop of the reactor facility. The number of such loops connected in parallel to the common header depends on the number of desalination modules in the NDC. Each multistage desalination module is equipped with a preliminary multistage self-evaporator which partially evaporates the third circuit water to heat the first DDP stages. The distillate is used to make up for the third circuit loop's water losses.

Structurally, the self-evaporator is part of the desalination module and is installed immediately next to the cascade of the evaporation stages. Such a layout with the preset reactor heat parameters makes it possible to achieve the maximum boiling temperature of $80^{\circ} \mathrm{C}$. The daily output of the NDC comprising one reactor and four desalination modules is around $35000 \mathrm{~m}^{3} /$ day. 
Figure 3 Seawater desalination using the RUTA reactor with modular channels for electricity production

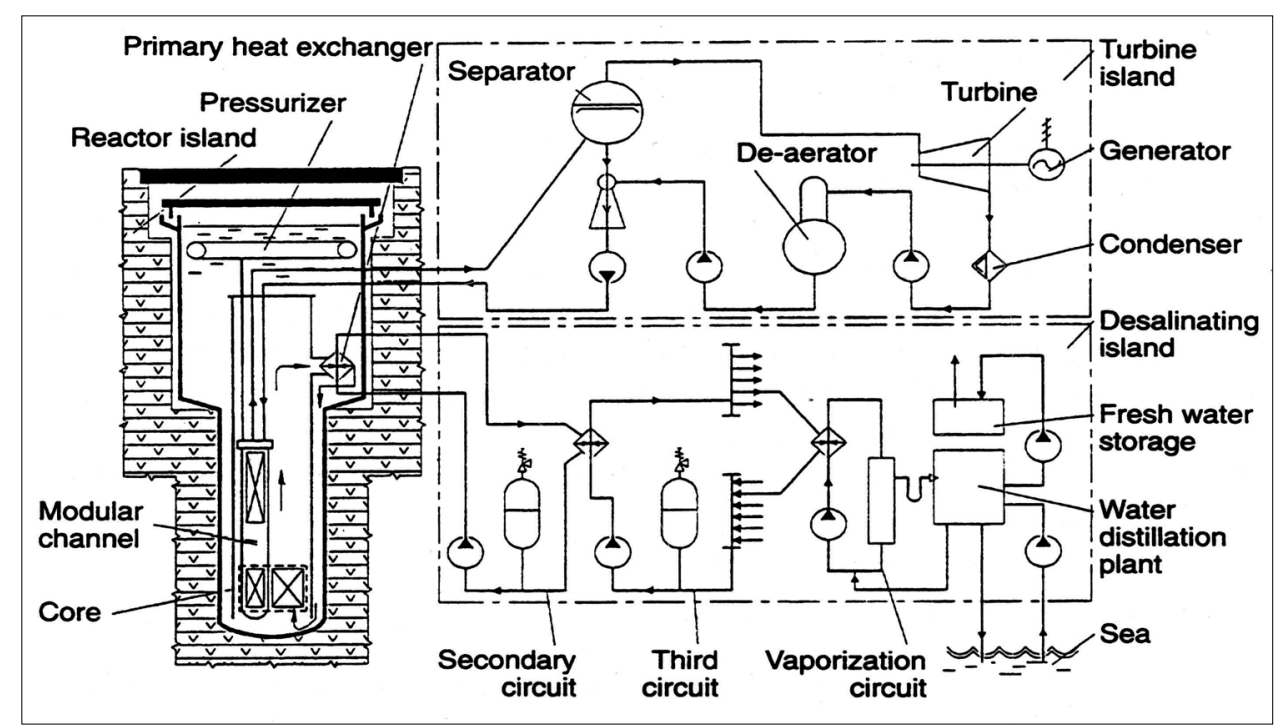

\section{Safety assurance}

Pool reactors are fairly widespread worldwide and are used largely for research purposes. They are commonly deployed within urban residential areas. The high safety level of pool reactors is achieved through their design features, which make it possible to resolve some of the major safety issues through the employment of the naturally inherent properties of the reactor. In a general case, the advantages offered by this reactor type are as follows:

- no excessive pressure in the reactor tank (pool), which makes it possible to avoid accidents with an instantaneous reactor tank rupture and loss of core cooling when it is uncovered

- a large amount and, therefore, a high accumulating capacity of the reactor pool water, which ensures a slow change of the coolant parameters during transients and emergencies and reliable heat removal from the fuel elements even if there is no controlled heat removal from the reactor core.

Apart from these features inherent in this reactor type, the design approaches used in the RUTA project give the reactor the following essential safety properties:

- There is a stabilisation of reactivity feedbacks determined by negative fuel and coolant temperature reactivity coefficients and by the positive density reactivity coefficient. This means that the heating up of the core structural components, including fuel, or the boiling of water in the core results in spontaneous reduction or self-limitation of the reactor's nuclear power at any initial position of the control rods, including the scram rods. 
- In the range of operating modes at power levels from the minimum controlled power level to $30 \% \mathrm{~N}_{\text {nom }}$, heat is removed from the core thanks to the natural coolant circulation in the reactor, thus ensuring reliable cooling of the fuel and passive cooldown of the reactor when it is shut down.

- Natural circulation in the secondary circuit provides for residual heat removal from the shutdown reactor and passive cooldown of the reactor facility in blackout emergencies.

- The loop arrangement of the primary circuit components, with the secondary circuit pressure exceeding the pool water pressure, ensures that the reactor coolant is localised within the reactor tank.

During development, the RUTA pool reactor had its safety enhanced considerably, thanks to the implementation of the defense-in-depth concept. This provides for several levels of devices, systems and operations to ensure the performance of the basic safety functions such as:

- control of the reactor power

- heat removal from the core

- confinement of radioactive product release.

To enable the reactor power control function, two independent reactor shutdown systems are provided. One of these performs the scram functions and the other, when actuated, ensures subcriticality for an unlimited time and with regard to any reactivity change effects, including emergency ones. Each of the systems performs its functions when at least one of the most effective control rod fails. When the CPS is deenergised, all CPS rods are inserted into the core by gravity.

Heat is removed from the reactor core via two independent channels. Each of these has three circuits with a consecutive pressure increase from the primary circuit via the secondary (intermediate) circuit to the third (network) circuit, which precludes the ingress of radioactive products to the network coolant.

During the disturbances and in emergencies, residual heat is removed through the natural coolant circulation in the reactor tank and in the secondary circuit in case of loss of power. When this happens, heat is removed from the secondary circuit through the emergency cooldown air system convectors with circulation of the air in the convector rooms.

The basic approach to the assurance of the RUTA facility's safety is consistent implementation of the defense-in-depth concept based on the use of a system of physical barriers to prevent the release of ionising radiation and radioactive substances into the environment and a multilevel system of engineered and organisational features to protect the barriers and keep them efficient. The system of physical barriers includes:

- the fuel matrix

- the fuel cladding

- a steel-lined reinforced-concrete reactor vessel (pool) with a leak-tight lid

- a leak-tight heat-exchange surface of the primary heat exchangers 
- leak-tight enclosures of the central hall rooms and the systems connected to the primary circuit

- leak-tight components and pipelines of the secondary circuit and leak-tight heat-exchange surfaces of the secondary and third circuit (network) heat exchangers.

The ingress of radioactive substances from the reactor to the network water is avoided through the following additional design approaches:

- the choking ratio of pressures in the heat exchangers of the reactor facility's primary and secondary circuits (the design-required top position of the secondary circuit relative to the reactor pool ensures that the secondary coolant pressure exceeds the reactor coolant pressure even when the secondary circuit loses the design-specified excess pressure in the event of depressurisation)

- the choking ratios of pressures in the second and third circuit heat exchangers.

The pressure reduction from the network circuit side in the heat exchanger may be caused by the disconnection of the heating network or by depressurisation of the heat supply line. The interim decrease in heat removed from the secondary circuit does not require prompt shutdown of the reactor and the reactor response will be rather slow. The danger of network circuit contamination, even if there are leaks in the network heat exchanger, is excluded because of the absence of radioactive products in the secondary coolant.

\section{Conclusions}

Thanks to its reactor design approaches and low coolant parameters, the RUTA facility features high reliability, utmost safety and environment friendliness, which make it possible to deploy NDHPs with the RUTA reactor in the immediate vicinity of the heat consumers. The simple reactor design and the reactor facility's major systems ensure good economic indicators with relatively low capital costs contributing to the low cost of produced heat.

Studies show that the construction of the first-of-its-kind unit in Obninsk, Russia, will pay back the investments through the heat supplied to consumers. At the same time, a wide range of scientific developments and the application of modern nuclear technologies in the production of new materials and the advancement of medicine can be carried out.

The development of innovative nuclear technologies based on the RUTA facilities appears to be promising also for other RUTA deployment places. The most attractive sites are cities involved in the nuclear industry, both in Russia and abroad, as well as research centres.

The construction of a multipurpose RUTA complex will provide the countries at the initial stage of developing their own nuclear programmes with a capability to create and commercialise advanced and cost-effective nuclear power technologies. This primarily includes the arrangement of production facilities and services based on nuclear and radiation technologies, the creation and expansion of the applied scientific research framework and the training of research and operating personnel for nuclear power plants as well as nuclear heat supplies to consumers. 


\section{References}

Adamov, E.O., et al. (1997) 'Inherently safe pool reactor as a generator of low-grade heat for district heating, air conditioning and salt water desalination', Nuclear Engineering and Design, Vol. 173, pp.167-174.

Romenkov, A.A., et al. (1997) 'The concept of co-generation nuclear plant (RUTA-TE) for seawater desalination', Proceedings of an International Symposium on Desalination of Seawater with Nuclear Energy, IAEA, Taejon, Korea, 26-30 May. 